\title{
CONTRIBUIÇÕES DA RELAÇÃO PROFESSOR-ALUNO NO CUIDADO À SAÚDE MENTAL DE ESTUDANTES: REVISÃO DA LITERATURA DE 2015 A 2020
}

\author{
Maria Manuela dos Santos ${ }^{1}$ \\ Faculdade de Ciências Humanas e Exatas do Sertão do São Francisco - FACESF \\ Liberalina Santos de Souza Gondim² \\ Faculdade de Ciências Humanas e Exatas do Sertão do São Francisco - FACESF
}

\section{RESUMO}

O presente artigo trata-se de uma revisão integrativa da literatura de 2015 a 2020 sobre as contribuições da relação professor-aluno no cuidado a saúde mental de estudantes. Teve como objetivo geral revisar a literatura de 2015 a 2020 sobre a importância da relação professor-aluno no cuidado ao sofrimento psíquico infanto-juvenil, e como objetivos específicos: descrever com base na literatura as estratégias utilizadas por professores para lidar com demandas de sofrimento psíquico advindas de alunos; e sintetizar os achados da literatura sobre os impactos das demandas dos alunos na saúde mental do educador. Trata-se de uma pesquisa qualitativa que analisou 21 artigos obtidos por meio das seguintes bases de dados: Scientific Electronic Library Online (SciELO), Portal periódico Capes e Biblioteca Virtual em saúde (BVS). Os resultados foram organizados em três eixos temáticos: estratégias utilizadas pelos educadores para lidar com o sofrimento psíquico dos alunos; relação professor - aluno como suporte na promoção de saúde mental do aluno; e fatores existentes no contexto escolar que influenciam na saúde mental dos professores. Os resultados demonstraram a importância da relação professor-aluno nos cuidados com o educando em sofrimento psíquico, porém as estratégias utilizadas pelos professores no suporte e cuidado são, em geral, baseadas no senso comum, de modo que lidar com as demandas de sofrimento dos estudantes pode gerar risco de adoecimento docente.

Palavras-chaves: Saúde mental, Professor, Aluno, Sofrimento Psíquico, Escola.

\footnotetext{
${ }^{1}$ Graduanda em Psicologia pela Faculdade de Ciências Humanas e Exatas do Sertão do São Francisco (FACESF). Belém De São Francisco, PE, Brasil.

${ }^{2}$ Mestre em Psicologia pela Universidade Federal do Vale do São Francisco (UNIVASF). Professora do curso de Psicologia da Faculdade de Ciências Humanas e Exatas do Sertão do São Francisco (FACESF), Belém De São Francisco, PE, Brasil.
} 


\title{
CONTRIBUTIONS OF THE TEACHER-STUDENT RELATIONSHIP IN THE STUDENT MENTAL HEALTH CARE: LITERATURE REVIEW FROM 2015 TO 2020
}

\begin{abstract}
This article is an integrative literature review from 2015 to 2020 on the contributions of the teacher-student relationship in the care of students' mental health. Its general objective was to review the literature from 2015 to 2020 on the importance of the teacher-student relationship in the care of children and adolescent psychological distress, and as specific objectives: describe, based on the literature, the strategies used by teachers to deal with psychological distress demands from students; and synthesize the findings of the literature on the impacts of students' demands on the educator's mental health. It is qualitative research that analyzed twenty-one articles obtained through the following databases: Scientific Electronic Library Online (SciELO), Portal periódico Capes e Biblioteca Virtual em saúde (BVS). The results were organized into three thematic axes: strategies used by educators to deal with students' psychological distress; teacher - student relationship as a support in promoting the student 's mental health; and existing factors in the school context that influence teachers' mental health. The results demonstrated the importance of the teacher-student relationship in caring for the student in psychological distress, however the strategies used by teachers in support and care are, in general, based on common sense, so that dealing with the students' suffering demands it can generate risk of teaching illness.
\end{abstract}

Keywords: Mental health, Teacher, Student, Psychic suffering, School.

\section{Introdução}

Está na constituição federal, art.208, I, que todas as crianças e adolescentes entre quatro e 17 anos devem estar devidamente matriculados em uma instituição de ensino (BRASIL, 1988). Além disso, a Lei de Diretrizes e Bases da Educação (LDB) estabelece o atendimento no contexto da Educação Infantil, Ensino Fundamental e Médio, com carga parcial mínima diária de quatro horas e sete horas para tempo integral (BRASIL, 1996). Entretanto, no caso do ensino médio, a Lei no 13.415/17 altera a LDB, de modo que, em seu Art. 13 aborda que com a política de implementação de escolas de Ensino Médio de Tempo Integral, as instituições de ensino dessa modalidade fornecerão atendimento de sete horas diárias (BRASIL, 2017). Logo, é possível perceber que esse aluno passara mais tempo dentro do contexto escolar.

Essa instituição de ensino também é configurada como um meio que proporciona relações sociais. A convivência pode despertar a afetividade, a simpatia e confiança, até mesmo quando não há de forma clara a existência mútua desses sentimentos. Esses alunos podem, nesse contexto, relatar ou demonstrar comportamentos que estão lhe causando prejuízo de uma forma geral, e essas atitudes podem ser decorrente de um sofrimento (D’ABREU; MARTURANO, 2019).

Retornando ao contexto frente a estadia do público infanto-juvenil no ambiente escolar e das relações construídas dentro desse espaço, os educadores além do seu convívio praticamente diário podem passar anos presente na vida de um determinado aluno (GARCIA, 2016). E com o passar do tempo, nesse período de convivência vão se construindo vínculos, entre eles o afetivo. Afetividade é vista por Vygotsky (1998, apud SAMPAIO; BRITO; CÂMARA; COUTINHO; LIMA, 
2017), como essencial no contexto a aprendizagem, vindo a contribuir na motivação e no interesse pelas atividades promovidas pelo educador, além de ser um fator de grande relevância nas relações diversas, influenciando nos sentimentos e nas ações.

Além do interesse pelas atividades propostas pelo professor, e da vontade de aprender, Lipp, Arantes, Buriti e Witzig (2002), acrescenta que a relação afetuosa pode fazer com que esse aluno perceba o seu professor como um companheiro, um apoio, alguém no qual pode conversar trocar ideias e pedir conselhos. Portanto, as demandas acumulativas referentes à vida desse aluno, as suas angústias, perturbações, conflitos internos e externos podem acabar surgindo.

Dados divulgados pela Organização Pan-Americana da Saúde/ Organização Mundial da Saúde (OPAS/OMS), mostram que, demandas referentes aos transtornos mentais continuam a crescer. Estima-se que em todo o mundo de $10 \%$ a $20 \%$ dos adolescentes vivenciem problemas de saúde mental, e $16 \%$ da carga global de doenças e lesões entre pessoas de 10 a 19 anos são resultantes dessas condições de adoecimento (BRASIL, 2018). Logo, retornando as informações presentes na constituição Federal, art.208, I, diante da matrícula de crianças e jovens, pode se afirmar que existe uma concentração significativa desse público dentro das escolas da Educação Básica brasileira.

Ainda no contexto escolar, porém voltado a saúde do educador, uma das profissões que mais apresentam problemas com relação à saúde mental é a do professor, destacando que, entre os fatores de relevância no agravamento do sofrimento mental da classe, estão às questões trazidas pelos alunos, seja com relação ao comportamento, dificuldades de aprendizagem, dificuldade nas relações tanto no ambiente escolar como fora dele e a preocupação do professor com o bem-estar do seu educando (DIEHL; MARIN, 2016; FERREIRA; SILVA, 2017; SILVA; COIMBRA; YOKOMISO, 2017; TOSTES; ALBUQUERQUE; SILVA; PETTERLE 2018). De modo que, por mais que esse professor esteja sobrecarregado e angustiado, parece não deixar o seu aluno sem um apoio, uma atenção.

A partir desses estudos e dos novos conceitos de saúde, levando em consideração os diversos fatores biopsicossociais e a implementação do conceito referente a promoção de saúde, a escola passou a ser vista como um espaço essencial no que se remete a prevenção e a promoção de saúde mental do público infanto-juvenil. Afinal, é nas escolas que a maior parte desse público está inserida (BRASIL, 2018; SOARES; ESTANISLAU; BRIETZKE; LEFÈVRE; BRESSAN, 2014)

Logo é possível perceber que a promoção de saúde mental dentro do contexto escolar é indispensável.

Objetivo da escola não deve ser apenas um lugar onde se produz educação e conhecimento de forma eficaz, mas um lugar onde exista interesse e que haja saúde de todos os seus membros, assim como, colaborar na formação de um pensamento crítico do estudante, que tenha como resultado a aquisição de práticas que visem promover, manter e recuperar a própria saúde (COSTA; FIGUEIREDO; RIBEIRO, 2013 apud SILVA; SOARES; SOUSA; KUSANO, 2019, p.134).

Entretanto, o professor, no seu período de formação, na grade curricular das instituições, é disponibilizado a disciplina de psicologia da educação. Ela pode ser apresentada como obrigatória ou eletiva, no entanto, é voltada a prática quanto ao desenvolvimento e aprendizagem educacional, não sendo suficiente para as demandas que vão além desse contexto (ALMEIDA, IZZI, 2007; MACHADO; COSTA, 2016; CID; SQUASSONI; GASPARINI, 2019). Portanto, essas colocações evidenciam o despreparo do professor e a necessidade de informações para lidar com demandas envolvendo sofrimento psíquico dos seus alunos, assim como, no enfrentamento na busca pela prevenção e promoção de saúde psíquica de todo o corpo escolar. 
Tendo em vista que o contexto escolar representa um lugar de grande relevância para o indivíduo, não apenas com relação à aprendizagem, mas sobre o seu desenvolvimento psicossocial, de modo a envolver relações sociais, emocionais e afetivas, torna-se um ambiente essencial para a construção do sujeito enquanto pessoa. O professor, por fazer parte desse conjunto configurado como peça indispensável e assídua, acaba convivendo diariamente com esse aluno, e no decorrer dessa vivência, são construídos vínculos importantes que favorecem tanto o desempenho escolar, quanto a relação socioemocional desse estudante. (PETRUCCl; BORSA; BARBOSA; KOLLER, 2014).

Dando continuidade ao diálogo, Sampaio et al. (2017), acrescentam que a relação construída entre professor e aluno, por vezes vai além dos conteúdos didáticos, existindo companheirismo e afinidades. Nessa convivência afetiva, o aluno pode acabar vendo o professor não só como um líder de sala que está ali para transpor conhecimento, mas um suporte ao qual pode recorrer quando preciso, ora para tirar dúvidas referente a disciplina ou para compartilhar acontecimentos da sua vida pessoal (SAMPAIO et al., 2017).

Seja em uma conversa, ou pela observação no comportamento da criança ou adolescente, o professor pode perceber quando existe algo de diferente, e de acordo sua formação, procura estratégias para descobrir o que está acontecendo. Nesse contexto, os educadores podem deparar-se com demandas quais não foram preparados para trabalhar, como a saúde psicológica dos educandos, de modo a gerar dificuldades para lidar e ajudar os seus alunos (SOARES, et al., 2014).

Segundo Estanislau e Bressan (2014), assuntos como saúde mental não são muito abordados nas escolas, as informações que chegam são bastante superficiais, não suprindo a necessidade dos profissionais da educação que lidam quase diariamente com essa demanda. No entanto, se esse professor tivesse as informações necessárias sobre o tema talvez conseguisse melhor auxiliar o seu aluno, assim como, detectar de forma efetiva sinais de adoecimento psíquico, sem confundir com comportamentos comuns para o público infanto-juvenil (ESTANISLAU; BRESSAN, 2014; SOARES, et al., 2014).

Levando em consideração o diálogo conduzido até aqui, Qual a importância da relação professor-aluno nos cuidados com a saúde mental dos estudantes?

Diante deste contexto, as hipóteses levantadas neste estudo foram: os professores têm a habilidade de identificar quando o seu aluno apresenta um comportamento diferente dos habituais; o conhecimento sobre o que é sofrimento psíquico e a capacidade do observar pode fazer dos professores uma peça-chave na detecção de sinais de um possível sofrimento psíquico; os educadores podem se tornar um facilitador na ajuda da promoção de saúde e enfrentamento ao sofrimento dos seus alunos; a saúde dos educadores pode ser afetada pelas demandas de sofrimento psíquico recebidas por parte dos alunos; o vínculo afetivo construído entre o professor e o alunos pode servir como apoio no enfrentamento ao sofrimento psíquico de alunos.

Após os argumentos levantados, evidencia-se a necessidade de realizar uma revisão de literatura sobre as contribuições da relação professor-aluno nos cuidados com a saúde mental do público infanto-juvenil, de modo que se possa tornar acessível essas informações para educadores e familiares e estudantes que possam se interessar pelo tema, além de contribuir para que pesquisadores da educação e da psicologia escolar possam explorar mais esse tema em investigações científicas futuras. Por fim, ter o acesso facilitado a produção brasileira atual sobre o tema, pode instigar o fortalecimento de políticas públicas de cuidados a saúde mental no contexto escolar, favorecendo a toda comunidade da referida instituição de ensino. 
O objetivo geral deste estudo foi revisar a literatura de 2015 a 2020 sobre a importância da relação professor-aluno no cuidado ao sofrimento psíquico infanto-juvenil. Os objetivos específicos foram descrever com base na literatura as estratégias utilizadas por professores para lidar com demandas de sofrimento psíquico advindas de alunos; e sintetizar os achados da literatura sobre os impactos das demandas dos alunos na saúde mental do educador.

\section{Metodologia}

A seguinte pesquisa trata-se de uma revisão integrativa de literatura, de modo qualitativo, no qual foi possível obter os artigos para a análise por meio eletrônico nas seguintes bases de dados: Scientific Electronic Library Online (SciELO), Portal periódico Capes e Biblioteca Virtual em saúde (BVS). O período estabelecido para busca de informações foi entre os anos de 2015 a 2020, no qual o levantamento de dados ocorreu entre agosto e setembro de 2020, com a proposta de conhecer o que tinha de mais atual na literatura para auxiliar os professores no suporte ao sofrimento psíquico dos estudantes.

Para melhor estratégia na efetuação da coleta de dados foram utilizados os seguintes descritores: Saúde mental, professor, aluno, sofrimento psíquico e escola. Ainda nesse contexto referente à coleta de dados, entre as várias tentativas na busca bibliográfica que contemplasse os objetivos desse estudo, os descritores foram aplicados em pares: "saúde mental" AND "professor"; "saúde mental" AND "aluno"; "saúde mental" AND "escola"; "sofrimento psíquico" AND "Professor"; "sofrimento psíquico" AND "Aluno" e "sofrimento psíquico" AND" escola"; "Professor" AND "aluno".

Feito a aplicação dos descritores, foi realizada uma filtragem do material com base nos critérios de inclusão e exclusão. Foram inclusos artigos em português que se encontravam nas bases de dados supracitadas, publicados entre 2015 e 2020 e que possuíssem algum dos descritores anteriormente apresentados. Foram excluídos artigos que não atendiam aos interesses da pesquisa fugindo do contexto de investigação, que não se encontravam de forma gratuita nas bases de dados escolhidas, que se repetiam nas mesmas, artigos de revisão e trabalhos não desenvolvidos no Brasil. Todas as descrições aqui definidas foram aplicadas diretamente ao filtro dos bancos de dados selecionados na busca bibliográfica.

Para concluir a seleção das literaturas a serem estudadas, os artigos resultantes da ação anterior foram organizados em um quadro Word 2010, podendo assim, identificar as repetições dos textos e uma breve análise de conteúdo. A partir dessa distribuição foi possível a última fase da coleta de dados, excluindo todos os artigos repetidos e os de conteúdo irrelevante para a temática. As informações aqui apresentadas com relação a seleção, foram organizadas em um fluxograma, para que assim tivéssemos uma melhor compreensão da filtragem dos dados a partir da aplicação dos critérios de inclusão e exclusão (Figura 1). 
Figura 1. Fluxograma do processo de seleção dos artigos.

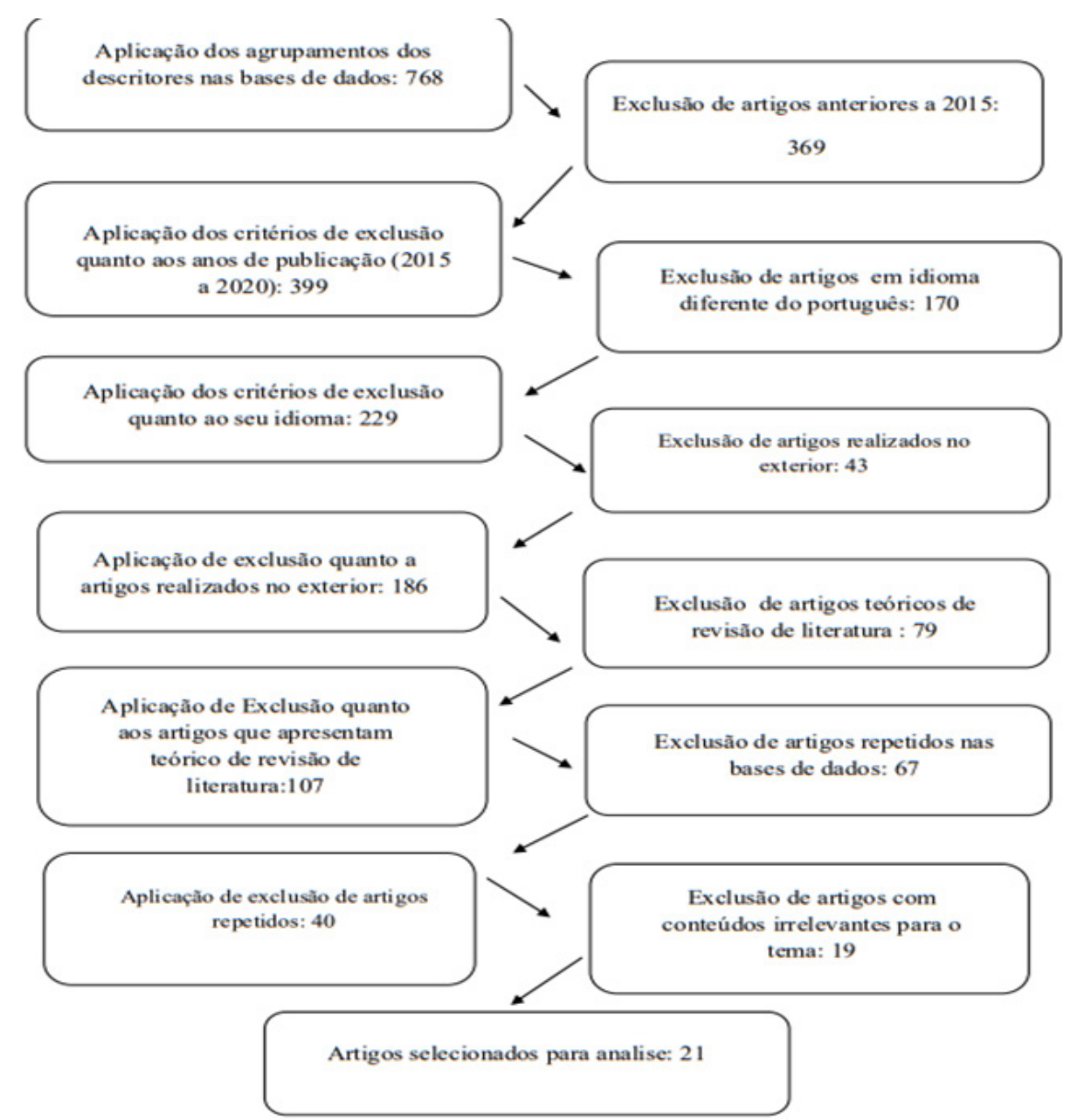

Fonte: Arquivos do próprio autor

Dessa forma, foi construído um quadro no Word 2010, no qual os textos foram organizados por ano, autor, periódico, método de pesquisa, Quali Capes, e público-alvo, possibilitando ao leitor conhecer as principais informações sobre os artigos utilizados para a obtenção dos resultados dessa pesquisa.

Com a seleção de artigos finalizada, eles foram distribuídos em tabelas Word 2010, para fichamento, possibilitando o estudo individual de cada obra, destacando os pontos principais de cada texto. Com esse estudo mais detalhado, foi possível perceber quais assuntos se destacaram, possibilitando uma melhor organização das ideias em três eixos temáticos: Estratégias utilizadas pelos educadores para lidar com o sofrimento psíquico dos alunos; Relação professor - aluno como suporte na promoção de saúde mental do aluno; e Fatores existentes no contexto escolar que influenciam na saúde mental dos professores. Esse método facilitou no processo frente à discussão dos achados, oferecendo melhor visualização do conteúdo.

Quanto aos aspectos éticos, riscos e benefícios, por se tratar de uma revisão de literatura integrativa, tendo todo o seu conteúdo obtido por meio de informações públicas, não oferece nenhum risco para a comunidade. Os benefícios estão na organização e atualização das informações frente ao objeto de pesquisa desse trabalho, favorecendo aos pesquisadores e leitores uma visão simplificada do que está sendo produzido sobre o contexto. 


\section{Desenvolvimento}

A partir do processo de busca por literaturas que contribuíssem para o conhecimento referente as demandas de início apresentadas nesse trabalho de pesquisa, obteve-se como resultado após toda a aplicação dos filtros, 21 textos. Nove $(42,85 \%)$ artigos foram publicados no ano de 2019; três $(14,28 \%)$ em 2018 ; três $(14,28 \%)$ pesquisas em 2020 ; três $(14,28 \%)$ estudos no período de 2017, dois (9,52\%) em 2016 e um (4,76\%) em 2015. Com essas informações é possível perceber que a maioria das literaturas se refere ao ano de 2019 , fazendo com que as informações desse estudo, fiquem entre o que se tem de mais atual sobre ao tema trabalhado.

Foi possível constatar que $12(57,14 \%)$ dos principais autores das respectivas literaturas são profissionais da área da psicologia, três $(14,28 \%)$ especialistas voltados a área educacional (Ciências humanas), três $(14,28 \%)$ especialistas em outras áreas das ciências da saúde (Enfermeiros, Psiquiatras). Entretanto, três $(14,28 \%)$ dos autores não foi possível identificar as respectivas áreas de atuação. Com relação aos dados referentes às profissões, queremos ressaltar que foi analisado apenas o primeiro autor das literaturas. Portanto, mesmo tendo os profissionais da psicologia como maioria, os aspectos aqui abordados não possuem uma área em específico para estudo. Logo, o temos como um assunto que está sendo abordado de forma interdisciplinar.

Ainda dentro desse contexto referente aos resultados das pesquisas, pode-se analisar as revistas quais os textos encontram-se publicados: 11 (52,38\%) estão em revistas voltadas a conteúdos referente à área da saúde, sete $(33,33 \%)$ educação e três $(14,28 \%)$ interdisciplinar (aberta a qualquer área de conhecimento). Na análise dos periódicos foi verificado o Qualis Capes das revistas, obtendo as informações na plataforma Sucupira, qual tem como objetivo mostrar o nível de confiabilidade atribuída à revista a partir das suas publicações (BARATA, 2016). Para chegarmos as classificações dos artigos, foram atribuídos aos filtros da plataforma, o título do periódico e uma área de estudo. Portanto, as avaliações aqui apresentadas são resultantes da pesquisa tendo como referência ao Qualis Capes das revistas para a área: psicologia.

De classificação A1 e A2 (periódicos de excelência internacional), constam quatro artigos (A1= 1 e A2 = 3) configurando aproximadamente $19,04 \%$ das literaturas desse trabalho, De B1 e B2 (periódicos de excelência nacional) constam 13 artigos (B1 $=6$ e B2 $=7$ ) configurando aproximadamente 61,9\%, De B3 a B5 (periódicos de média relevância), constam três artigos (B3=1, B4=1 e B5=2) configurando aproximadamente $19,04 \%$ dos achados. Levando em consideração a qualidade da maioria das literaturas utilizadas, os artigos encontrados, em geral, trazem informações seguras, enriquecendo o nível de confiança aos leitores em ter como fonte de conhecimento esse estudo.

Quanto a metodologia, foi constatado que 14 dos 21 artigos representando aproximadamente $66,66 \%$ dos achados utilizam do método qualitativo descritivo/ exploratório, um estudo representando aproximadamente 4,76\% utilizam o método quantitativo descritivo/experimental, quatro representando aproximadamente $14,2 \%$ são quantitativos transversais e dois dos achados configurando $9,82 \%$ fazem uso do método misto (quantitativo-qualitativo).

Quadro 1. Classificação dos artigos quando aos anos de publicação, periódicos, métodos e Qualis.

\begin{tabular}{|lllcccc|}
\hline $\begin{array}{l}\text { No de } \\
\text { artigos }\end{array}$ & Anos & Autores & Títulos & Periódicos & $\begin{array}{c}\text { Métodos } \\
\text { utilizados }\end{array}$ & $\begin{array}{c}\text { Qualis } \\
\text { Capes }\end{array}$ \\
\hline 1 & 2019 & AUDA et al. & $\begin{array}{c}\text { Percepção de professores } \\
\text { sobre ações de grupos de } \\
\text { reconhecimento emocional }\end{array}$ & $\begin{array}{c}\text { Journal of } \\
\text { Nursing and } \\
\text { Health }\end{array}$ & $\begin{array}{c}\text { Qualitativo } \\
\text { descritivo/ } \\
\text { Exploratório }\end{array}$ & B3 \\
\hline
\end{tabular}




\begin{tabular}{|c|c|c|c|c|c|c|}
\hline 2 & 2019 & $\begin{array}{l}\text { FERREIRA, } \\
\text { PEDRO }\end{array}$ & $\begin{array}{l}\text { Níveis de ansiedade e depressão } \\
\text { entre professores do Ensino } \\
\text { Infantil e Fundamental }\end{array}$ & Pro-Posições & $\begin{array}{l}\text { Quantitativa/ } \\
\text { Experimental }\end{array}$ & B2 \\
\hline 3 & 2019 & CID et al. & $\begin{array}{c}\text { Saúde mental infantil e contexto } \\
\text { escolar: as percepções dos } \\
\text { educadores }\end{array}$ & Pro-Posições & $\begin{array}{l}\text { Qualitativo } \\
\text { descritivo / } \\
\text { Exploratório }\end{array}$ & B2 \\
\hline 4 & 2019 & WIEZZEL & $\begin{array}{c}\text { Repercussões do } \\
\text { desenvolvimento emocional } \\
\text { infantil aos processos } \\
\text { socializadores na escola: } \\
\text { contribuições à relação } \\
\text { professor-aluno }\end{array}$ & Nucleus & $\begin{array}{l}\text { Qualitativo } \\
\text { descritivo / } \\
\text { Exploratório }\end{array}$ & B5 \\
\hline 5 & 2017 & SAMPAIO et al. & $\begin{array}{c}\text { Processos Afetivos Na Relação } \\
\text { Professor E Aluno: Reflexões } \\
\text { Sobre A Mediação Do Psicólogo } \\
\text { Escolar }\end{array}$ & $\begin{array}{l}\text { Revista } \\
\text { Expressão } \\
\text { Católica }\end{array}$ & $\begin{array}{l}\text { Qualitativo } \\
\text { descritivo/ } \\
\text { Exploratório }\end{array}$ & B5 \\
\hline 6 & 2020 & GABRIEL et al. & $\begin{array}{l}\text { Autolesão não suicida entre } \\
\text { adolescentes: significados para } \\
\text { profissionais da educação e da } \\
\text { Atenção Básica à Saúde }\end{array}$ & $\begin{array}{l}\text { Escola } \\
\text { Anna Nery } \\
\text { Revista de } \\
\text { enfermagem }\end{array}$ & $\begin{array}{l}\text { Qualitativo } \\
\text { descritivo/ } \\
\text { Exploratório }\end{array}$ & B1 \\
\hline 7 & 2018 & TOSTES et al. & $\begin{array}{l}\text { Sofrimento mental de } \\
\text { professores do ensino público }\end{array}$ & $\begin{array}{l}\text { Saúde em } \\
\text { debate }\end{array}$ & $\begin{array}{l}\text { Quantitativo / } \\
\text { Transversal }\end{array}$ & B2 \\
\hline 8 & 2019 & BARBOSA & $\begin{array}{c}\text { Práticas educativas em saúde } \\
\text { mental: a } \\
\text { escola como espaço para a } \\
\text { ruptura dos } \\
\text { estigmas sobre a doença mental }\end{array}$ & $\begin{array}{l}\text { Revista } \\
\text { Principia }\end{array}$ & $\begin{array}{l}\text { Qualitativa } \\
\text { descritiva / } \\
\text { Exploratória }\end{array}$ & B4 \\
\hline 9 & 2019 & HAMANN et al. & $\begin{array}{l}\text { Consultoria em Psicologia } \\
\text { Escolar: Relato de Experiência } \\
\text { cia em Curso Pré-Vestibular }\end{array}$ & $\begin{array}{l}\text { Psicologia } \\
\text { escolar e } \\
\text { educacional }\end{array}$ & $\begin{array}{l}\text { Qualitativo } \\
\text { descritivo / } \\
\text { Exploratório }\end{array}$ & $\mathrm{A} 2$ \\
\hline 10 & 2018 & $\begin{array}{l}\text { COUTINHO, } \\
\text { CARNEIRO, } \\
\text { SALGUEIRO }\end{array}$ & $\begin{array}{c}\text { Vozes de crianças e } \\
\text { adolescentes: o que dizem da } \\
\text { escola? }\end{array}$ & $\begin{array}{l}\text { Psicologia } \\
\text { escolar e } \\
\text { educacional }\end{array}$ & $\begin{array}{l}\text { Qualitativo } \\
\text { descritivo / } \\
\text { Exploratório }\end{array}$ & $\mathrm{A} 2$ \\
\hline 11 & 2019 & OSTI, TASSONI. & $\begin{array}{l}\text { Afetividade percebida e sentida: } \\
\text { representações de alunos do } \\
\text { ensino fundamental }\end{array}$ & $\begin{array}{l}\text { Caderno de } \\
\text { pesquisa }\end{array}$ & $\begin{array}{l}\text { Qualitativo- } \\
\text { Quantitativo / } \\
\text { Exploratório }\end{array}$ & $\mathrm{A} 2$ \\
\hline 12 & 2020 & BRITO et al. & $\begin{array}{l}\text { Comportamento suicida e } \\
\text { estratégias de prevenção sob a } \\
\text { ótica de professores }\end{array}$ & $\begin{array}{l}\text { Escola } \\
\text { Anna Nery } \\
\text { Revista de } \\
\text { enfermagem }\end{array}$ & $\begin{array}{l}\text { Qualitativo- } \\
\text { Quantitativo / } \\
\text { Exploratório }\end{array}$ & B1 \\
\hline 13 & 2019 & $\begin{array}{l}\text { SOUZA, } \\
\text { PANUNCIO, } \\
\text { FIORATI. }\end{array}$ & $\begin{array}{l}\text { Crianças e adolescentes } \\
\text { em vulnerabilidade social: } \\
\text { bem-estar, saúde mental e } \\
\text { participação em educação. }\end{array}$ & $\begin{array}{l}\text { Caderno } \\
\text { Brasileiro } \\
\text { de Terapia } \\
\text { Ocupacional }\end{array}$ & $\begin{array}{l}\text { Qualitativo- } \\
\text { Quantitativo / } \\
\text { Exploratório }\end{array}$ & B2 \\
\hline 14 & 2019 & AKAHOSI et al. & $\begin{array}{c}\text { A intersetorialidade no campo } \\
\text { da saúde mental infanto-juvenil: } \\
\text { proposta de atuação da terapia } \\
\text { ocupacional no contexto } \\
\text { escolar }\end{array}$ & $\begin{array}{l}\text { Caderno } \\
\text { Brasileiro } \\
\text { de terapia } \\
\text { Ocupacional }\end{array}$ & $\begin{array}{l}\text { Qualitativo } \\
\text { descritivo/ } \\
\text { Experimental }\end{array}$ & B2 \\
\hline 15 & 2016 & GAUY & $\begin{array}{l}\text { Crianças e adolescentes } \\
\text { com problemas emocionais } \\
\text { e comportamentais têm } \\
\text { necessidade de políticas de } \\
\text { inclusão escolar? }\end{array}$ & $\begin{array}{l}\text { Educar em } \\
\text { revista }\end{array}$ & $\begin{array}{l}\text { Qualitativo } \\
\text { descritivo / } \\
\text { Exploratório }\end{array}$ & B1 \\
\hline 16 & 2018 & $\begin{array}{l}\text { ALBUQUERQUE } \\
\text { et al. }\end{array}$ & $\begin{array}{l}\text { Exploração e sofrimento mental } \\
\text { de professores: um estudo na } \\
\text { rede estadual de ensino do } \\
\text { Paraná }\end{array}$ & $\begin{array}{l}\text { Trabalho, } \\
\text { Educação e } \\
\text { Saúde }\end{array}$ & $\begin{array}{l}\text { Qualitativo } \\
\text { descritivo / } \\
\text { Exploratório }\end{array}$ & B1 \\
\hline
\end{tabular}




\begin{tabular}{|c|c|c|c|c|c|c|}
\hline 17 & 2020 & APARICIO et al. & $\begin{array}{l}\text { Identificação de emoções } \\
\text { e sentimentos: estudo } \\
\text { exploratório com alunos do } \\
\text { ensino básico }\end{array}$ & $\begin{array}{c}\text { Acta } \\
\text { Paulista de } \\
\text { Enfermagem }\end{array}$ & $\begin{array}{l}\text { Qualitativo } \\
\text { descritivo / } \\
\text { Exploratório }\end{array}$ & B2 \\
\hline 18 & 2017 & PARAVENTI et al. & $\begin{array}{l}\text { Mediação grupal como } \\
\text { estratégia de ressignificação da } \\
\text { queixa escolar }\end{array}$ & $\begin{array}{l}\text { Pesquisa } \\
\text { e pratica } \\
\text { psicossocial }\end{array}$ & $\begin{array}{l}\text { Quantitativo } \\
\text { descritivo / } \\
\text { Experimental }\end{array}$ & B2 \\
\hline 19 & 2017 & $\begin{array}{l}\text { SILVA, } \\
\text { COIMBRA, } \\
\text { YOKOMISO. }\end{array}$ & $\begin{array}{l}\text { Saúde dos professores do } \\
\text { ensino fundamental da } \\
\text { rede pública e a construção } \\
\text { dos espaços psíquicos } \\
\text { compartilhados. }\end{array}$ & $\begin{array}{l}\text { Revista } \\
\text { Vínculo }\end{array}$ & $\begin{array}{l}\text { Quantitativo/ } \\
\text { Transversal }\end{array}$ & B1 \\
\hline 20 & 2015 & $\begin{array}{l}\text { CARNEIRO, } \\
\text { COUTINHO }\end{array}$ & $\begin{array}{l}\text { Infância e adolescência: como } \\
\text { chegam as queixas escola res à } \\
\text { saúde mental? }\end{array}$ & $\begin{array}{l}\text { Educar em } \\
\text { revista }\end{array}$ & $\begin{array}{l}\text { Quantitativo/ } \\
\text { Transversal }\end{array}$ & B1 \\
\hline 21 & 2016 & $\begin{array}{l}\text { COSTA, } \\
\text { SILVA }\end{array}$ & $\begin{array}{l}\text { Ansiedade e depressão: o } \\
\text { mundo da pratica docente e o } \\
\text { adoecimento psíquico }\end{array}$ & $\begin{array}{l}\text { Estudos de } \\
\text { Psicologia }\end{array}$ & $\begin{array}{l}\text { Quantitativo/ } \\
\text { Transversal }\end{array}$ & $\mathrm{A} 1$ \\
\hline
\end{tabular}

Fonte: Arquivos do próprio autor

Sobre o nível escolar do público estudado em cada artigo, três $(14,28 \%)$ das literaturas são voltadas a Educação Infantil, um (4,76\%) a Educação Infantil e Ensino Fundamental, oito (38,09\%) ao Ensino Fundamental, seis (28,57\%) Ensino Fundamental e Médio e dois (9,52\%) exclusivamente ao Ensino Médio. Além disso, um dos artigos teve como participantes profissionais de psicologia escolar.

O quadro 2 representa a classificação dos artigos quanto aos níveis, ciclos e faixas etárias do público escolar estudado. As informações obtidas foram distribuídas por número do artigo, autor e ano de publicação, níveis e faixas etárias predefinidas para cada público. Os dados referentes às faixas etárias e os ciclos foram apresentadas com base na LDB (Brasil, 1996).

Quadro 2. Classificação dos artigos quando ao nível, ciclo e faixa etária escolar

\begin{tabular}{|c|c|c|c|c|c|c|}
\hline \multirow{3}{*}{$\begin{array}{l}\text { № de } \\
\text { artigos }\end{array}$} & \multirow{3}{*}{ Autor/Ano } & \multirow{3}{*}{ Níveis escolares } & \multicolumn{4}{|c|}{ Faixas etárias previstas (idade) } \\
\hline & & & E.I & $19 \mathrm{C}$ & $2 \circ \mathrm{C}$ & $3 \circ \mathrm{C}$ \\
\hline & & & 0 a 5 & 6 a 10 & 11 a 14 & 15 a 17 \\
\hline 1 & AUDA et al. (2019) & Ensino fundamental & & & $\mathrm{X}$ & \\
\hline 2 & FERREIRA, PEDRO (2019) & $\begin{array}{l}\text { Educação Infantil e } \\
\text { Fundamental }\end{array}$ & $\mathrm{x}$ & $\mathrm{x}$ & & \\
\hline 3 & CID et al. (2019) & Educação Infantil & $\mathrm{X}$ & & & \\
\hline 4 & WIEZZEL (2019) & Educação Infantil & $x$ & & & \\
\hline 5 & SAMPAIO et al. (2017) & \multicolumn{5}{|c|}{ Estudo realizado com profissionais da psicologia } \\
\hline 6 & GABRIEL et al. (2020) & $\begin{array}{c}\text { Ensino Fundamental e } \\
\text { Médio }\end{array}$ & & & $\mathrm{X}$ & $\mathrm{x}$ \\
\hline 7 & TOSTES et al. (2018) & $\begin{array}{c}\text { Ensino Fundamental e } \\
\text { Médio }\end{array}$ & & & $x$ & $x$ \\
\hline 8 & BARBOSA (2019) & Ensino Médio & & & & $x$ \\
\hline 9 & HAMANN et al. (2019) & Ensino Médio & & & & $x$ \\
\hline 10 & $\begin{array}{l}\text { COUTINHO, CARNEIRO, } \\
\text { SALGUEIRO (2018) }\end{array}$ & Ensino Fundamental & & $x$ & $x$ & \\
\hline
\end{tabular}




\begin{tabular}{|c|c|c|c|c|c|c|}
\hline 11 & OSTI, TASSONI. (2019) & Ensino Fundamental & & $x$ & & \\
\hline 12 & BRITO et al. (2020) & Ensino Fundamental & & & $x$ & \\
\hline 13 & $\begin{array}{l}\text { SOUZA, PANUNCIO, } \\
\text { FIORATI. (2019) }\end{array}$ & $\begin{array}{l}\text { Ensino Fundamental e } \\
\text { Médio }\end{array}$ & & $x$ & $x$ & $x$ \\
\hline 14 & AKAHOSI et al. (2019) & Educação Infantil & $x$ & & & \\
\hline 15 & GAUY (2016) & $\begin{array}{l}\text { Ensino fundamental e } \\
\text { Médio }\end{array}$ & & $x$ & $x$ & $x$ \\
\hline 16 & $\begin{array}{l}\text { ALBUQUERQUE et al. } \\
\qquad(2018)\end{array}$ & $\begin{array}{l}\text { Ensino Fundamental e } \\
\text { Médio }\end{array}$ & & $x$ & $x$ & $x$ \\
\hline 17 & APARICIO et al. (2020) & Ensino Fundamental & & & $x$ & \\
\hline 18 & PARAVENTI et al. (2017) & Ensino Fundamental & & $x$ & $x$ & \\
\hline 19 & $\begin{array}{l}\text { SILVA, COIMBRA, } \\
\text { YOKOMISO. (2017) }\end{array}$ & Ensino Fundamental & & $x$ & $x$ & \\
\hline 20 & $\begin{array}{c}\text { CARNEIRO, COUTINHO } \\
(2015)\end{array}$ & $\begin{array}{l}\text { Ensino Fundamental e } \\
\text { Médio }\end{array}$ & & $x$ & $x$ & $x$ \\
\hline 21 & COSTA SILVA (2016) & Ensino Fundamental & & $x$ & $x$ & \\
\hline
\end{tabular}

Legenda: E.I (Educação Infantil); C (Ciclo).

Fonte: Arquivos próprios do autor. Classificação baseada na LDB (BRASIL, 1996).

Com base nos achados a partir da investigação de conteúdo, foi possível perceber e organizar os textos de acordo com os seguintes eixos temáticos: Estratégias utilizadas pelos educadores para lidar com o sofrimento psíquico dos alunos; Relação professor - aluno como suporte na promoção de saúde mental do aluno; e Fatores existentes no contexto escolar que influenciam na saúde mental dos professores. Estes temas serão detalhados a seguir.

\section{Estratégias utilizadas pelos educadores para lidar com o sofrimento psíquico dos alunos}

Um dos papeis do professor em sala de aula é a observação, esse profissional tem a habilidade de reconhecer todo o funcionamento e o comportamento rotineiro apresentado por seus alunos, assim como, identificar fatores que interferem no desenvolvimento frente a aprendizagem do educando. Entretanto, podem surgir demandas que por vezes acabam fugindo das habilidades desenvolvidas e aprendidas na sua formação enquanto transmissor de conhecimento.

Seis dos artigos selecionados, trazem narrativas de alguns professores retratando como tem sido as suas experiências frente à demanda aqui destacada. Em quatro literaturas, esses profissionais da educação afirmam utilizar conhecimentos de senso comum, estratégias de cunho pessoal, atentando-se as experiências vivenciadas no seu próprio contexto familiar (SILVA; COIMBRA; YOKOMISO, 2017; CID; SQUASSONI; GASPARINI, 2019; GABRIEL; COSTA; CAMPEIZ; SALIM; SILVA; CARLOS, 2020; BRITO; SILVA JÚNIOR; COSTA; SALES; GONÇALVES; MONTEIRO, 2020).

Em duas das literaturas, foi possível perceber o quanto esse profissional encontra-se desassistido, tendo que lidar com quase nenhuma ferramenta ou suporte nos cuidados referente às possíveis situações advindas dos seus alunos, e por muitas vezes sem nenhum conhecimento prévio sobre saúde mental e aspectos relacionados. Quando tentam conseguir algum tipo de informação, no intuito de promover trabalhos referentes ao assunto, partem para pesquisas buscando informações de forma solitária (GABRIEL, et al., 2020; CID; SQUASSONI; GASPARINI, 2019).

Além das informações já apresentadas referente à como agem diante de possíveis sinais de sofrimento psíquico apresentados pelos alunos, em especial a "Autolesão não suicida", assunto tra- 
tado por Gabriel, et al. (2020) e Brito et al. (2020), os autores relatam através das falas de alguns dos seus entrevistados, que mesmo não possuindo materiais de apoio, esses profissionais tentam lidar da melhor forma possível, utilizando de estratégias como a aproximação a partir dos vínculos construídos na relação professor-aluno, oferecendo escuta e acolhida (GABRIEL, et al., 2020; BRITO, et al., 2020).

Entre os textos, um faz referências as relações a partir de um viés afetivo, destacando que durante a busca por estratégias para lidar com os comportamentos apresentados pelos alunos, os professores adotam técnicas voltadas ao envolvimento afetivo, deixando transparecer a sua preocupação e empatia, tentando fortalecer ainda mais a confiança entre o educando e o educador, podendo assim, ter mais chances de conhecer as angústias do discente (CID; SQUASSONI; GASPARINI, 2019).

Ainda nessa análise referente as ações dos professores, foi possível constatar a recorrência as famílias na tentativa de um diálogo que venha a oferecer suporte ao professor nessa relação de atenção e cuidados, assim como, propor um possível encaminhamento as redes de apoio, que por sua vez, podem vir a serem falhas, principalmente pela dificuldade encontrada por algumas instituições de conseguir um atendimento (SILVA; COIMBRA; YOKOMISO, 2017).

Outro assunto que chamou bastante atenção, refere-se justamente a questão dos encaminhamentos feitos pelas escolas às redes de apoio ou a sistema de referência em saúde mental. No artigo de Carneiro e Coutinho, (2015), a escola é tida como um dos órgãos que mais identifica e encaminham crianças e adolescentes aos setores da psiquiatria.

Entretanto, quando o assunto é informação, foi possível perceber que pouco ou quase nada se sabe do assunto "saúde mental", "sofrimento psíquico" e "adoecimento", até mesmo, desconhecem o real trabalho dos profissionais ligados a saúde mental (Psicólogos e psiquiatras). E Pela falta de conhecimento dentro da escola, acabam discriminando comportamentos e desconhecendo situações que possam estar sendo gatilhos para algumas situações, sejam elas, de cunho emocional ou não (HAMANN; CONSONI; ALCÂNTARA; GAMALHO; DIPP, 2019; CID; SQUASSONI; GASPARINI, 2019).

É justamente a partir da análise, que nos deparamos com mais um questionamento feito por um dos autores. Como é que esse educador está realizando essa identificação, e escolhendo para qual dispositivo encaminhar esse aluno se pouco conhece sobre os referidos temas? (CARNEIRO; COUTINHO, 2015, p.190).

A partir dessa colocação feita pelos autores citados nessa discussão, podemos nos atentar ao fato de que o professor está ligado às demandas que chegam ao sistema de saúde. Logo, ele tem contato direto com o alunado que após uma avaliação profissional pode vir ou não a ser diagnosticado com algum adoecimento. Entretanto, foi possível notar que o nível de conhecimento do professor com relação aos conceitos de saúde mental é baixo e que mesmo) assim, continua agindo como um identificador de sinais, mostrando que algo está "errado" com o aluno, tal como, podem deixar escapar comportamentos que talvez sejam significativos para a saúde psíquica do estudante.

\section{Relação professor - aluno como suporte na promoção de saúde mental do aluno.}

Nos artigos que fizeram parte da amostra deste estudo, não foi encontrado literatura com o objetivo de estudar especificamente a relação professor-aluno como suporte nos cuidados de discente em sofrimento mental. O que evidencia uma lacuna que precisa ser preenchida por estudos futu- 
ros. Entretanto, em oito dos artigos foi possível destacar alguns fatores os quais fazem referência a importância da relação professor-aluno, ressaltando alguns pontos tidos como essenciais que ajudam os profissionais da educação na aproximação com seu alunado, assim como, na possibilidade de melhores resultados através de intervenções referente a promoção de saúde, em especial da saúde mental desse público, principalmente em conjunto com especialistas ou redes de apoio.

Wiezzel (2019) aborda a relação professor e aluno como semelhante às relações familiares, e exemplifica destacando o "público infantil", descrevendo que a criança tenta encontrar no professor algo próximo ao que busca ou espera encontrar em casa.

Como o assunto chega à comparação com os vínculos familiares, alguns dos textos trabalham a questão de quão próximo esses profissionais estão dos seus alunos, refletindo o aspecto convivência a longo prazo, fazendo do corpo escolar, de um modo geral, detentores de conhecimento frente a personalidade e comportamento de cada um dos estudantes (AUDA; BRAGA; TEIXEIRA JÚNIOR; FERREIRA, 2019; SAMPAIO, et al., 2017).

Em um dos achados, qual se refere à própria atuação do psicólogo no contexto escolar, trata como é importante essa relação, em especial os vínculos afetivos, como um dos facilitadores do seu trabalho (SAMPAIO et al., 2017). Gabriel, et al. (2020) corrobora com Sampaio, et al. (2017), a partir do seu estudo dizendo que é difícil conhecer esse educando na sua totalidade de imediato, e a partir do apoio dado pelos professores ou membros do corpo escolar, pode facilitar o contato e obter melhor resultados nas propostas de possíveis intervenções, assim como, nas formulações de estratégias que envolvam a promoção de saúde de uma forma geral (SAMPAIO, et al. 2017; GABRIEL, et al., 2020).

Voltando ao texto de Wiezzel (2019), o autor destaca que pode ocorrer dessa relação não ser tão amistosa, e o aluno apresentar um comportamento de indisciplina e agressividade. Entretanto, ele descreve os atos como resultante de um possível sofrimento. Entre os aspectos relacionados estão às mudanças presenciadas pelos alunos na infância, especialmente as transformações ambientais, junto com as percas, inclusive a troca de professores, podem fazer com que esses alunos, na tentativa de evitar mais dor e angústia, acabe por recusar-se a desenvolver vínculos com os novos professores, protegendo-se através dos comportamentos agressivos (WIEZZEL,2019).

Contudo, quando essa relação professor-aluno se faz de forma amigável e afetuosa produz benefícios tanto para o professor como para o aluno, por isso, é importante investir no fortalecimento dos vínculos e da confiança (COUTINHO; CARNEIRO; SALGUEIRO, 2018). Levando em consideração, Barbosa (2019), vem reforçar a importância tanto do professor como da escola nos cuidados frente à promoção de saúde, tendo o ambiente escolar como meio no qual se pode possibilitar a ruptura de estigmas e preconceitos referente ao tema "saúde mental", assim como, promover saúde, tendo como ferramentas de apoio não só o professor, mas todo o corpo educacional (BARBOSA, 2019).

Dois textos trazem no seu conteúdo, o apelo por políticas que venham ajudar o professor a lidar com essas demandas, servindo como ferramenta de apoio na promoção de saúde e na identificação segura de possíveis sinais de adoecimento mental (OSTI; TASSONI; 2019, FERNANDES; CID; SPERANZA; COPI, 2019).

\section{Fatores existentes no contexto escolar que influenciam na saúde mental dos professores}

Entre os 21 artigos selecionados, sete deles trazem algumas informações referente a saúde mental dos professores, assim como, fatores os quais podem estar interferindo na saúde 
deles. O estudo de Tostes, et al. (2018), apresenta algumas questões referente a saúde do professor de modo geral. Entretanto, acaba destacando algumas informações referente a saúde mental do referido público. No texto aqui citado, foi realizada uma pesquisa entre os professores do ensino público do Paraná, participando 1.021 educadores. Os dados levantados demonstram que $23,73 \%$ dos entrevistados apresentam algum fator referente à saúde mental, dentre eles: depressão, ansiedade e estresse. Destacando-se o público feminino como o que mais apresenta demandas relacionadas ao adoecimento mental (TOSTES, et al., 2018).

Os possíveis influenciadores descritos nos textos acabam variando. Existem aspectos que apontam fatores estruturais (estrutura escolar, remuneração e materiais de trabalho) e relacionais, envolvendo questões direcionadas a relação entre os membros escolares, alunos e familiares (TOSTES, et al., 2018).

Levando em consideração a relação professor, aluno e família, na maioria das literaturas analisadas que fazem referência a essa temática "Saúde mental do professor", foi possível identificar o comportamento agressivo e a indisciplina por parte dos alunos, como possíveis atuantes no adoecimento mental dos profissionais da educação (ALBUQUERQUE; LIRA.; SANTOS JÚNIOR; CHIOCHETTA; PERNA; SILVA, 2018; COSTA; SILVA, 2019; TOSTES, et al., 2018; FERREIRA; PEDRO, 2018; BRITO, et al., 2020). Aqueles que trabalham com o público infantil, tem acrescentado à falta de apoio das famílias como agravante (FERREIRA; PEDRO, 2018).

Um aspecto bastante curioso que foi possível observar em um dos textos relaciona-se, ao fato de que os professores que lecionam em turmas do ensino fundamental, em especial nas séries iniciais, apresentam maiores índices de sofrimento mental (TOSTES, et al., 2018). Entretanto, um segundo artigo, traz na sua análise que os professores que trabalham com o ensino médio estão mais insatisfeitos com o seu público, trazendo mais uma vez questões relacionadas ao comportamento (indisciplina e agressividade) dos seus estudantes (FERREIRA; PEDRO, 2018).

Dentre os achados, em especial os que tratam de questões voltadas a visão do professor diante do sofrimento mental dos seus alunos, não foram encontrados textos os quais, relacionassem diretamente comportamento advindos de um possível sofrimento mental do educando com a saúde mental do educador. Entretanto, em três das literaturas, Souza, Panuncio e Fiorati (2019), Gabriel et al. (2020), e Brito, et al. (2020), com base nas respostas dadas pelos profissionais da educação participantes, foi possível perceber a preocupação e angústia vivenciada por eles diante de alguns dos comportamentos apresentados. Duas das literaturas que mais chamaram atenção com relação à percepção do professor foram referentes ao comportamento suicida e não suicida. Em Brito, et al. (2020), uma professora relata a sua experiência com relação ao comportamento autolesivo, no qual foi vivenciado dentro da própria sala de aula. Ainda dentro do contexto, os professores relatam a angústia, preocupação e o quanto esses momentos marcam suas vidas (GABRIEL, et al., 2020; BRITO, et al., 2020).

É possível que o profissional se sinta mexido por presenciar tais situações, com a sensação de impotência diante de um comportamento de tamanha gravidade, o qual pode vir a acontecer outras vezes, talvez não dentro da sala de aula, mas em outra parte do ambiente escolar. Esse tipo de demanda poderá surgir na vida de muitos outros professores. Portanto, é importante a capacitação desses profissionais, além do apoio de órgãos e trabalhadores da área da saúde em específico, no intuito de fornecer suporte a toda essa comunidade. Enfatizando a saúde do educador, podem ser desenvolvidos projetos interventivos ligados à promoção de saúde de forma integral a categoria, além de desenvolver novos estudos voltados a saúde mental do professor, levando em consideração a relação existente entre esse profissional e comportamentos apresentados pelos alunos, resultantes de um possível sofrimento psíquico ou adoecimento mental. 


\section{Considerações finais}

A escola tem um papel bastante significativo na vida das pessoas, pois, na maioria das vezes, passa-se uma parcela da nossa existência em uma instituição de ensino. Esse ambiente faz-se presente cada vez mais cedo na rotina, e por tempos mais longos.

No decorrer desse estudo, foi possível fortalecer a percepção do quanto o sistema educacional é importante para o desenvolvimento presente e das futuras gerações. É um ambiente indispensável, que necessita de mais atenção, investimentos e cuidados não só em relação à estrutura física, mas tudo que compõem a instituição.

Foi possível perceber a precariedade da profissão professor, assim como, a sobrecarga enfrentada pela área, e quanto esse fator tem prejudicado ainda mais a saúde desse público. Entretanto, a força de vontade existente em cada um, faz com que continuem lutando por melhorias, podendo assim, estar oferecendo o que sabem fazer de melhor, transformação.

Quanto aos alunos, em especial o público infanto-juvenil, existe uma demanda referente à saúde mental deles, porém, os trabalhos e intervenções voltadas ao contexto aparecem de forma tímida, mesmo existindo decretos, portarias, bases legais que apoiam a articulação entre saúde e escola.

A literatura analisada demonstrou que o professor lida quase que diariamente com demandas advindas dos seus alunos, seja de cunho educacional ou emocional, tentando conduzir da melhor forma possível, diante das possibilidades do contexto. Porém, os estudos apresentados nesta revisão abordam as contribuições da relação professor-aluno nos cuidados referente ao adoecimento psíquico infanto-juvenil de uma forma abrangente, havendo lacuna no que diz respeito aos elementos específicos dessa relação que precisa ser preenchida por estudos futuros. Ainda assim, os estudos demonstram que essa relação é significativa e que o professor pode ser visto como uma figura importante no suporte a promoção de saúde mental dos educandos.

Sobre as estratégias utilizadas pelos professores para lidar com o sofrimento psíquico dos alunos foi possível perceber que alguns professores têm lidado com seus alunos utilizando estratégias de senso comum, se apoiando aos vínculos afetivos e a confiança, que nem sempre são suficientes para contemplar as demandas do aluno, podendo inclusive interferir na própria saúde e bem-estar do educador. Assim, aspectos como as demandas vindas dos seus alunos, em especial a agressividade e a indisciplina, além de emoções despertadas nos docentes ao presenciar comportamentos suicidas e autolesões não suicidas dentro do contexto escolar, podem prejudicar a saúde mental desse educador.

Logo, as informações do parágrafo anterior, além de estarem respondendo alguns dos objetivos, contribuíram com uma das nossas hipóteses sendo ela a seguinte: a saúde do educador pode ser afetada pelas demandas de sofrimento psíquico vindas dos alunos. Como é possível perceber, a agressividade e a indisciplina segundo Wiezzel (2019), pode ser reflexo de um possível sofrimento psíquico. Portanto, esses comportamentos estão presentes entre os aspectos existentes dentro do contexto escolar que influenciam a saúde mental do professor, levando a crer que demandas de sofrimento vinda dos alunos podem interferir na saúde mental do educador, fazendo com que essa hipótese seja respondida.

Em relação a hipótese inicialmente estabelecida de que o educador pode se tornar um facilitador na ajuda da promoção de saúde e enfrentamento ao sofrimento dos seus alunos, foi possível encontrar embasamento no autor Gabriel et al. (2020), ao destacar que a relação professor-aluno, a partir dos vínculos afetivos e da confiança, aliado ao trabalho dos profissionais 
da saúde, contribuem para a promoção de saúde dentro do contexto escolar. Já sobre a hipótese de que o vínculo afetivo construído entre o professor e os alunos pode servir como apoio no enfrentamento ao sofrimento psíquico do educando, foi evidenciado que a relação afetiva entre professor-aluno representa um papel significativo para estratégias de promoção de saúde, não descartando essa possibilidade de também servir como estratégia para o enfrentamento de um possível sofrimento mental. Porém, são necessários mais estudos para fomentar tal perspectiva.

Sobre a hipótese de que o conhecimento sobre o que é sofrimento psíquico e a capacidade do observar pode fazer dos professores uma peça-chave na detecção de sinais de um possível sofrimento psíquico, os estudos incluídos nesta amostra não evidenciaram esse ponto diretamente, porém, autores como Carneiro e Coutinho (2015) aponta que a escola é um dos órgãos que mais identificam e encaminham jovens ao setor de psiquiatria. Logo, entende-se que a obtenção de informações, treinamentos e formações sobre saúde mental e sofrimento psíquico, pode contribuir para a melhor compreensão docente sobre o tema e facilitar possíveis articulações entre saúde e educação.

Ainda fazendo uma reflexão sobre os achados, surgiram alguns fatores que devem ser levados em consideração e estudados em pesquisas futuras. Um deles é o encaminhamento dos alunos aos setores de psiquiatria pelos professores. Logo, como funciona? E quais critérios são apontados como determinantes encaminhamento? Ainda dentro da proposta, talvez seja importante compreender a fundo o real conhecimento teórico dos profissionais da educação sobre saúde mental, sofrimento psíquico e adoecimento.

Outro tema que surgiu e merece ser investigado é a relação entre as famílias de crianças e adolescentes que estão em sofrimento psíquico e os professores, levando em consideração, a ausência dos pais dentro do contexto escolar, e como isso pode afetar a saúde do professor e a do aluno em sofrimento.

Ressalta-se ainda a importância de se pensar em ações de promoção e prevenção de saúde direcionadas ao contexto escolar, levando em consideração a relação professor-aluno e a saúde mental deles. Diante dessas perspectivas, uma das possibilidades é o fortalecimento das ações intersetoriais entre os órgãos educacionais a nível municipal e estadual, junto com os órgãos de saúde para o desenvolvimento de projetos, podendo inclusive promover formações sobre o tema "saúde mental" a todo o corpo escolar.

É evidente que professor é um detector de sinais, mas não detém conhecimento para diagnosticar e nem propor estratégias de cuidado a um aluno que se encontre adoecido, entretanto junto com um psicólogo que é um dos profissionais abeis a tal tarefa poderá auxiliar durante um possível processor de prevenção dentro da escola. Logo, pode-se acrescentar que a proposta desse estudo não é trazer as responsabilidades do profissional de Psicologia ou qualquer um outro profissional da área da saúde para o professor, mas tentar fazer com que esse público seja melhor cuidado e informado sobre os fatores que remetem a saúde, em especial a saúde mental. Possibilitando ao professor diante da ausência de um cuidador especializado, melhor lidar com tal situação, assim como, encaminhar e oferecer apoio antes e durante esse processo qual o aluno terá que enfrentar, além desse educador poder ser melhor assistido e cuidado.

Por tratar-se de uma revisão de literatura, com foco nas publicações referentes aos trabalhos realizados no Brasil e que estivessem em português, uma limitação deste estudo foi não haver contato direto com o público docente e nem leituras de trabalhos estrangeiros. Consequentemente, talvez se tenha perdido informações que poderiam vir a acrescentar e enriquecer ainda mais a pesquisa. Além disso, a não definição de uma faixa etária para estudo, pode ter interferido na identificação de especificidades da relação dos professores com o público infantil, que 
diferem no público adolescente no modo de cuidado a saúde mental. Em vista disso, fica aberta a possibilidade de ampliação deste estudo em futuras investigações relativas ao tema.

\section{Referências}

ALBUQUERQUE, G. S. C.; LIRA, L. N. A.; SANTOS JÚNIOR, I. S.; CHIOCHETTA, R. L.; PERNA, P. O.; SILVA, M. J. S. Exploração e sofrimento mental de professores: um estudo na rede estadual de ensino do Paraná. Trab. educ. saúde, Rio de Janeiro, v. 16, n. 3, p. 1287-1300, 2018. Disponível em: <http://www.scielo.br/scielo.php?script=sci_arttext\&pid=S198177462018000301287\&ln$\mathrm{g}=e n \& n r m=i s o>$. Acesso em: 28 Set. 2020. Doi: http://dx.doi.org/10.1590/1981-7746-sol00145.

ALMEIDA, P.C.A.; AZZI, R.G. A psicologia da educação como um saber necessário para a formação de professores. Temas psicol. [online]. v.15, n.1, p. 41-55, 2007. Disponível em: <http://pepsic.bvsalud.org/scielo.php?script=sci_abstract\&pid=\$1413389X2007000100006\&lng=pt\&nr$\mathrm{m}=\mathrm{iso}>$. Acesso em: 15. Abril. 2020.

AUDA, J.M.; BRAGA, G. C.; TEIXEIRA JÚNIOR, S.; FERREIRA, M. J. Percepção de professores sobre ações de grupos de (re)conhecimento emocional. J. nurs. health. v.9, n.2, 2019. Disponível em: $<$ https://periodicos.ufpel.edu.br/ojs2/index.php/enfermagem/article/view/16400>. Acesso em: 15.Set.2020.DOI: https://doi.org/10.15210/jonah.v9i2.16400

BARBOSA, V.F.B. Práticas educativas em saúde mental: a escola como espaço para a ruptura dos estigmas sobre a doença mental. Revista Principia: Divulgação Científica e Tecnológica do IFPB, n. 46, p. 11-18, 2019. Disponível em: <https://periodicos.ifpb.edu.br/index.php/ principia/article/view/2267>. Acesso em: 16. Set.2020. Doi: http://dx.doi.org/10.18265/ 1517-03062015v1n46p11-18.

BRASIL, Folha informativa,Saúde mental dos adolescentes, Determinantes Sociais e Riscos para a Saúde, Doenças Crônicas Não Transmissíveis e Saúde Mental. 2018, OPAS/OMS. Disponível em: $\quad$ https://www.paho.org/bra/index.php?option=com_content\&view=article\&id=5779:foIha-informativa-saude-mental-dos adolescentes\&Itemid=839>. Acesso em: 24.Mar. 2020.

BRASIL, Constituição da República Federativa do Brasil. Brasília, 5 de outubro de 1988. Disponível em: <https://www2.camara.leg.br/atividade-legislativa/legislacao/constituicao1988.html>. Acesso em: 24. Mar.2020.

BRASIL. Lei no 9.394, de 20 de dezembro de 1996. Estabelece as diretrizes e bases da educação nacional. Diário Oficial da União, Brasília, 23 de dezembro de 1996. Disponível em:<http://www. planalto.gov.br/ccivil_03/leis/L9394.htm>. Acesso em: 11. Dez. 2020

BRASIL. Lei $n$ 13.415, de 16 de fevereiro de 2017. Altera as Leis $\mathbf{n} \mathbf{0}$ 9.394, de 20 de dezembro de 1996, que estabelece as diretrizes e bases da educação nacional. Diário Oficial da União, Brasília, 16 de fevereiro de 2017. Disponível em: <https://www.planalto.gov.br/ccivil_03/_Ato20152018/2017/Lei/L13415.htm> Acesso em: 12. Dez.2020

BARATA, R.C.B. Dez coisas que você precisa saber sobre o Qualis. RBPG, Brasília, v. 13, n.30, p. 13-40, 2016. Disponível em: <http://ojs.rbpg.capes.gov.br/index.php/rbpg/article/view/947/ pdf>. Acesso em: 16.Nov. 2020. Doi: http://dx.doi.org/10.21713/2358-2332.2016.v13.947.

BRITO, M.D.L.S.; SILVA JÚNIOR, F. J. G.; COSTA, A. P. C.; SALES, J. C. S.; GONÇALVES, A. M. S.; MONTEIRO, C. F. S. Comportamento suicida e estratégias de prevenção sob a ótica de profes- 
sores. Esc. Anna Nery, Rio de Janeiro: v. 24, n. 4, 2020. Disponível em: <http://www.scielo.br/ scielo.php?script=sci_arttext\&pid=S1414-81452020000400214\&Ing=en\&nrm=iso $>$. Acesso em: 28 Set. 2020.Doi: https://doi.org/10.1590/2177-9465-ean-2020-0109.

CID, M. F. B.; SQUASSONI, C. E.; GASPARINI, D. A. Saúde mental infantil e contexto escolar: as percepções dos educadores. Pro-Posições [online]. v. 30, 2019. Campinas, 2019. Disponível em:<https://www.scielo.br/scielo.php?script=sci_arttext\&pid=S0103-73072019000100509>. Acesso em: 22. Abril.2020. Doi: https://doi.org/10.1590/1980-6248-2017-0093.

CARNEIRO, C.; COUTINHO, L.G. Infância e adolescência: como chegam as queixasescolarà saúde mental? Educ. ver, Curitiba: n. 56, p. 181-192, 2015. Disponível em:<http://www.scielo.br/ scielo.php?script=sci_arttext\&pid=S0104-40602015000200181\&Ing=en\&nrm=iso $>$. Acesso em: 12 Out. 2020. Doi:https://doi.org/10.1590/0104-4060.37764.

COUTINHO, L.G.; CARNEIRO, C.; SALGUEIRO, L.M. Vozes de crianças e adolescentes: o que dizem da escola? Psicol. Esc. Educ., Maringá: v. 22, n. 1, p. 185-193, 2018. Disponível em: <http://www. scielo.br/scielo. php?script=sci_arttext\&pid=S1413-85572018000100185\&lng=en\&nrm=iso $>$. Acesso em: 25 Out. 2020. Doi: https://doi.org/10.1590/2175-35392018014739.

COSTA, R. Q. F. da; SILVA, N. P. Níveis de ansiedade e depressão entre professores do Ensino Infantil e Fundamental. Pro-Posições, Campinas: SP, v. 30, p. 1-29, 2019. Disponível em: <https://periodicos.sbu.unicamp.br/ojs/index.php/proposic/article/view/8656506>. Acesso em: 5 Nov. 2020.

D'ABREU, L.C.F.; MARTURANO, E.M. Associação entre comportamentos externalizantes e baixo desempenho escolar: uma revisão de estudos prospectivos e longitudinais. Estud. Psicol., Natal: v. 15, n. 1, p. 43-51, 2010. Disponível em: <http://www.scielo.br/scielo.php?script=sci_arttext\&pid=S1413-294X2010000100006\&lng=en\&nrm=isso >.Acesso em: 21Abril.2020. doi: https:// doi.org/10.1590/S1413-294X2010000100006.

DIEHL, L.; MARIN, A.H. Adoecimento mental em professores brasileiros: revisão sistemática da literatura. Est. Inter. Psicol. Londrina: v. 7, n. 2, p. 64.85, 2016. Disponívelem: <http://pepsic. bvsalud.org/scielo.php?script=sci_arttext\&pid=S2236-64072016000200005\&lng=pt\&nrm=iso>. Acessos em: 04. Abril. 2020

ESTANISLAU, G.; BRESSAN, R.A. R. Saúde Mental Na Escola: o que os educadores devem saber. Porto Alegre: Artmed,2014.

FERREIRA, R.Q.C.; PEDRO, S.N. Níveis de ansiedade e depressão entre professores do Ensino Infantil e Fundamental. Pro-Posições. Campinas: v.30, 2019. Disponível em:<http://www.scielo. $\mathrm{br} / \mathrm{scielo}$.php?script=sci_arttext\&pid=S0103-73072019000100503\&lng=en\&nrm=iso>. Acesso em: twenty-nine. Março.2020. doi: https://doi.org/10.1590/1980-6248-2016-0143.

FERNANDES, A.D.S.A.; CID, M. F. B.; SPERANZA, M.; COPI, C. G. Intersectoriality in the field of childand adolescent mental health: proposal of occupational therapy in the school context. Cad. Bras. Ter. Ocup., São Carlos: v. 27, n. 2, p. 454-461, 2019. Disponível em: <http://www.scielo.br/ scielo.php?script=sci_arttext\&pid=S2526-89102019000200454\&lng=pt\&nrm=iso $>$. Acessos em: 28 Set. 2020. Doi:https://doi.org/10.4322/2526-8910.ctore1660.

GARCIA, J.M. Saúde Mental na Escola: O que os Educadores Devem Saber. Psico-USF, Itatiba: v. 21, n. 2, p. 423-425, 2016. Disponível em: <http://www.scielo.br/scielo.php?script=sci_arttex$\mathrm{t} \& \mathrm{pid}=S 141382712016000200423 \&$ Ing=en\&nrm=isso $>$. Acesso em: 03. Abril. 2020. Doi: https:// doi.org/10.1590/1413-82712016210217. 
GABRIEL, I.M.; COSTA, L. C. R.; CAMPEIZ, A. B.; SALIM, N. R.; SILVA, M. A. I.; CARLOS, D. M. Autolesão não suicida entre adolescentes: significados para profissionais da educação e da Atenção Básica à Saúde. Esc. Anna Nery, Rio de Janeiro: v. 24, n. 4, 2020. Disponível em: <http://www. scielo.br/scielo.php?script=sci_arttext\&pid=S1414-81452020000400218\&lng=en\&nrm=iso>. Acesso em: 23. Sete. 2020. Doi: http://dx.doi.org/10.1590/2177-9465-ean-2020-0050.

HAMANN, C.; CONSONI, M.; ALCÂNTARA, R.; GAMALHO, A.; DIPP, R. P. Consultoria em Psicologia Escolar: Relato de Experiência em Curso Pré-Vestibular. Psicol. Esc. Educ., Maringá: v. 23, 2019. Disponível em: <http://www.scielo.br/scielo.php?script=sci_arttext\&pi$d=S 1413-85572019000100603 \&$ Ing=en\&nrm=isso >. Acesso em: 26. Set. 2020. Doi: https://doi. org/10.1590/2175-35392019018505.

LIPP, M.E.N.; ARANTES, J. P.; BURITI, M. S.; WITZIG, T. O estresse em escolares. Psicol. Esc. Educ. (Impr.). Campinas: v. 6, n. 1, p. 51-56, 2002.Disponível em: <http://www.scielo.br/scielo.php?script=sci_arttext\&pid=S141385572002000100006\&lng=en\&nrm=iso>. Acesso em: 08.Abril. 2020. Doi: https://doi.org/10.1590/S1413-85572002000100006.

MACHADO, C.A.; COSTA, L.B. Ensino de Psicologia na formação de professores: uma aproximação com diálogos possíveis. Pro-Posições, Campinas: v. 27, n. 2, p.221-234,2016. Disponível em: $\quad$ http://www.scielo.br/scielo.php?script=sci_arttext\&pid=S010373072016000200221\&lng=en\&nrm=iso >. Acesso em: 03 Abril. 2020. Doi: https://doi.org/10.1590/1980-6248-20140063.

PARAVENTI, L.; SCAFF, L.; CORD, D.; OLTRAMARI, L. Mediação grupal como estratégia de ressignificação da queixa escolar. Pesq. e Prá. Psicossociais, v. 12 .n.3, São João del Rei, 2017. Disponível em :< http://pepsic.bvsalud.org/pdf/ppp/v13n1/14.pdf> acesso em : 26. Set .2020

PETRUCCI, G.W.; BORSA, J. L.; BARBOSA, A. J. G.; KOLLER, S. H. Adaptação cultural e evidências de validade da Escala de Relacionamento Professor-Aluno. Aval. psicol., Itatiba: v. 13, n. 1, p. 133-142, 2014. Disponível em:<http://pepsic.bvsalud.org/scielo.php?script=sci_arttext\&pi$d=S 1677-04712014000100016 \&$ lng=pt\&nrm=isso $>$. Acessos em: 29 Maio. 2020.

SAMPAIO, A.B.A.; BRITO, H. R. N. G.; CÂMARA, C. M. F.; COUTINHO, E. M. C.; LIMA, J. M. C. Processos afetivos na relação professor e aluno: Reflexões sobre a mediação do Psicólogo escolar. Revista Expressão Católica, v. 6, n.1,p.54-62, 2017. Disponível em: <http://publicacoesacademicas.unicatolicaquixada.edu.br/index.php/rec/article/view/2071>. Acesso em: 22.Abril. 2020. Doi:http://dx.doi.org/10.25190/rec.v6i1.2071.

SILVA, G.V.; SOARES, J. B.; SOUSA, J. C.; KUSANO, L. A. E. Promoção de saúde mental para adolescente em uma escola de ensino médio:Um relato de experiência. Rev. NUFEN, Belém: v. 11, n. 2 , p. 133.148, 2019. Disponível em: <http://pepsic.bvsalud.org/scielo.php?script=sci_arttext\&pid=S2175-25912019000200009\&Ing=pt\&nrm=iso>. Acessos em: 27. Abril. 2020. Doi: http:// dx.doi.org/10.26823/RevistadoNUFEN.vol11.no02rex28.

SILVA, V.A.; COIMBRA, A.K.S.; YOKOMISO, C.T. Saúde dos professores do ensino fundamental da rede pública e a construção dos espaços psíquicos compartilhados. Vínculo, São Paulo: v. 14, n. 2, p. 58-69, 2017. Disponível em: <http://pepsic.bvsalud.org/scielo.php?script=sci_arttext\&pid=S1806-24902017000200008\&lng=pt\&nrm=iso>. Acessos em: 24. Abril. 2020.

SOARES, A.G.S.; ESTANISLAU, G.; BRIETZKE, E.; LEFÈVRE, F.; BRESSAN, R. A. Percepção de professores de escola pública sobre saúde mental. Rev. Saúde Pública, São Paulo: v. 48, n. 6, p. 940-948, 2014. Disponível em:<http://www.scielo.br/scielo.php?script=sci_arttext\&pi- 
$d=S 003489102014000600940 \& \operatorname{lng}=e n \& n r m=i s o>$.Acesso em: 30 Março. 2020. Doi: https://doi. org/10.1590/s0034-8910.2014048004696.

SOUZA, L.B.; PANUNCIO, M.P.P.; FIORATI, R.C. Crianças e adolescentes em vulnerabilidade social: bem-estar, saúde mental e participação em educação. Cad. Bras. Ter. Ocup, São Carlos: v. 27, n. 2, p. 251-269, 2019. Disponível em: <http://www.scielo.br/scielo.php?script=sci_arttext\&pid=S2526-89102019000200251\&lng=en\&nrm=iso>. Acesso em: 25 Out. 2020. Doi: http://dx.doi. org/10.4322/2526-8910.ctoao1812.

TOSTES, M.V.; ALBUQUERQUE, G. S. C.; SILVA, M. J. S.; PETTERLE, R. R. Sofrimento mental de professores do ensino público. Saúde em debate, Rio de Janeiro: v. 42, n. 116, p. 87-99, 2018. Disponível em: <http://www.scielo.br/scielo.php?script=sci_arttext\&pid=S010311042018000100087\&ln$\mathrm{g}=e n \& n r m=i s o>$. Acesso em 24. Abril. 2020. Doi: https://doi.org/10.1590/0103-1104201811607.

WIEZZEL, A.C. Repercussões do desenvolvimento emocional infantil aos processos socializadores na escola: contribuições à relação professor-aluno. Nucleus, v.16, n.2, 2019. Disponível em:<http://www.nucleus.feituverava.com.br/index.php/nucleus/article/view/3096> Acesso em: 12. Setembro. 2020. Doi: https://doi.org/10.3738/1982.2278.3096. 